\title{
Processing of the Pyrite Concentrates to Generate Sulfurous Anhydride for Sulfuric Acid Production
}

\author{
T.A. Chepushtanova, V.A. Luganov
}

Kazakh National Technical University after K. I. Satpayev

Contact: + 011-7-327-2680139, Satpayev St., b.22, zip code - 050013,

E-mail: tanya2305@list.ru, pichnya@ rambler.ru

\begin{abstract}
The results of two-stage roasting of pyrite concentrate with air blowing and the principle scheme of the process are presented in the report.

The results of experimental sulfuric acid production tests using pyrite concentrate to generate sulfurous rich gas containing $0.1-0.15 \%$ of sulphur trioxide are shown. Comparative characteristics with technologies known for the present are given.
\end{abstract}

Keywords: roast, pyrite, sulfuric anhydride, sulfurous anhydride

\section{INTRODUCTION}

Traditionally the basic sources of raw material for production of sulfuric acid are sulphur and iron (sulfuric) pyrites. About half of sulfuric acid is produced from sulfur and one third is from pyrite. Discharge gases from the processing of nonferrous metals which contain sulphur dioxide make up the rest [1].

With the purpose of environment protection all over the world measures are being taken to use industrial wastes containing sulphur. Sulfur dioxide discharged from the waste gases of power plants and metallurgical plants amounts considerably more than that is used for production of sulfuric acid. Due to the low $\mathrm{SO}_{2}$ concentration in these waste gases, their processing is not always possible for the present [2-3]. Among the raw materials for sulfuric acid production, the waste gas is the cheapest; the wholesale prices for pyrites are also low, while sulfur is the most expensive [6]. Therefore, to achieve the economic expediency of sulfuric acid from sulfur, the scheme should be developed where the cost of sulfuric acid processing must be essentially lower than the cost of processing pyrites or waste gases.

In this work, a two-stage roasting technology of pyrite with sulfurous anhydride production by economically and ecologically expedient method is presented. 


\section{MATERIALS AND METHODS}

\subsection{Materials}

Initial pyrite concentrate contained $49.8 \%$ sulphur, $43-86 \%$ of iron, $0.133 \%$ of cobalt, $2.4 \%$ of $\mathrm{SiO}_{2}, 0.57 \%$ of $\mathrm{Al}_{2} \mathrm{O}_{3}$, and $0.72 \%$ of $\mathrm{CaO} .89 .5 \%$ of the material had the size less than 0.1 Mm. The moisture content was $1.2 \%$.

\subsection{Methods}

Semi-industrial tests of pyrrhotite roasting in autogenous regime at $22 \%$ blowing oxygen content and $20-25^{\circ} \mathrm{C}$ lattice temperature were conducted on the device as shown in Fig. 1. The device includes the furnace, fluidized bed (operation area $0,33 \mathrm{~m}^{2}$ ) with the mobile heating chamber, loading and unloading system and dust trapping system.

\section{RESULTS AND DISCUSSION}

Concentration of sulphur dioxide in the roasting gas depends on the ratio of sulphur and air fed for burning. If the air is taken in stoichiometric quantity, that is, 1 mole of oxygen for every mole of sulfur, the concentration of sulfur dioxide will be equal to the volume share of the oxygen in the air $(\mathrm{Cso} 2 \cdot \max =21 \%)$ in case of the full sulfur burning. However, the air is usually taken in excess because otherwise the temperature in the furnace will be too high.

In the case of adiabatic sulphur burning, the roasting temperature for reaction mixture of stoichiometric composition will be $1500^{\circ} \mathrm{C}$. In practical conditions, possibilities of temperature rise in the furnace are limited by the fact that the lining of the furnace and gas pipes is quickly destroyed if the temperature is higher than $1300{ }^{\circ} \mathrm{C}$. Usually, the roasting gas during sulfur burning is produced with $13-14 \%$ of $\mathrm{SO}_{2}$.

We know that the method of sulphatizing roasting of sulfide material containing non-ferrous metals with sulfurous gas production in the furnace of fluidized bed use oxygen-air blowing in 2 stages. The first stage takes place during the roasting of initial material up to pyrrhotite with the shortage of the oxygen in the blowing. The second stage involves the sulfatizing roasting of this product with the excess of the oxygen. The distributions of the total oxygen-air blowing in two stages are in parallel [4]. The roasting gases from both stages are joined, and the cinder is removed at the second stage. Production gas contains $12-18 \%$ of $\mathrm{SO}_{2}, 4-9 \%$ of $\mathrm{O}_{2}$, $0,4-1.5 \%$ of $\mathrm{SO}_{3}$, and the dust of iron sulfates. But such a method has a lot of shortcomings: significant content of sulfur anhydride in production gas, not high concentration of sulphurous anhydride in it (12-18\%), and a small extent of the consumption of the blowing oxygen.

There is also a method where a production gas contains $15 \%$ of $\mathrm{SO}_{2}$ and $6 \%$ of $\mathrm{O}_{2}, 0,5-2.5 \%$ of $\mathrm{SO}_{3}$, with the use of $70 \%$ of oxygen, and also the dust of iron sulfates [5-6]. But this method also has a number of essential shortcomings: increased 
content of elemental sulphur in gases at the pyrrhotizing (the first) stage, and complexity in apparatus for the dust collection system.

Thus, the purpose of this work is to obtain the production gas which practically doesn't contain sulphur anhydride while simultaneously has an increase of the sulfurous anhydride content in it.

We developed a technology of two-stage roasting of pyrite concentrate on the basis of the air blowing with production of the rich sulphurous gas containing minimal quantity of sulphur trioxide. This involves autogenous two-stage pyrrhotizing roasting with $60-65 \%$ of elemental sulfur removal and transforming it into $\mathrm{SO}_{2}$ at the first stage and the removal of the remained 35-40\% sulfur with produced $\mathrm{Fe}_{3} \mathrm{O}_{4}$ in the cinder at the second stage.

\subsection{First stage of roasting}

The essence of the method is in the following: the autogenous roasting production of sulfide materials of the cinder and the pure production of gas suitable for direct processing to produce sulfuric acid without containing sulfur anhydride and oxygen is achieved by transformation of $60-65 \%$ of sulfur of pyrite into $\mathrm{SO}_{2}$ in the first stage. A number of reactions take place in this process and after this, sulfur anhydride which came with the gas is completely destroyed and the total oxygen of the blowing is used up. Semi-industrial tests of pyrrhotizing roasting in autogenous regime were conducted on the device as shown in Fig. 1.

In the process of tests we regulated: velocity of concentrate feeding, mazut and air consumption; and controlled: resistance of the layer; discharge under the arch, temperature under the lattice, in the layer (3 locations), under the lattice, in cyclone, in the chamber of final burning, and in accumulating coolers; the content of the oxygen, carbon dioxide and sulphurous anhydride in gases.

The study has achieved autogenous pyrrhotizing roasting at specific capacity of $26-29 \mathrm{t} / \mathrm{m}^{2}$.day with desulphurization of $60-65 \%$. Produced solid roasting product is pyrrhotite $\left(\mathrm{Fe}_{1-\mathrm{x}} \mathrm{S}\right)$ with $20-25 \%$ iron oxides. The extent of oxygen use exceeds 95\%. Average sulphur extraction into gas: $49,34 \%$ from the cinder, $40,10 \%$ from the dust. Iron and sulphur content in cinder corresponds to the extent of pyrite dissociation $95-96.5 \%$, and in cyclone dust $74-75 \%$. Concentrate of different size classes are present with layers created from different time, and it has different extent of pyrite dissociation. Fine dust trapped in the electrical filter is partly oxidized while coming through the chamber of final sculpture burning. Gases produced in the process contain in the average of $16.7-17 \%$ sulfurous anhydride and $0.1-0.5 \%$ of oxygen. This corresponds to the extent of oxygen use in the layer with more than $95 \%$. 


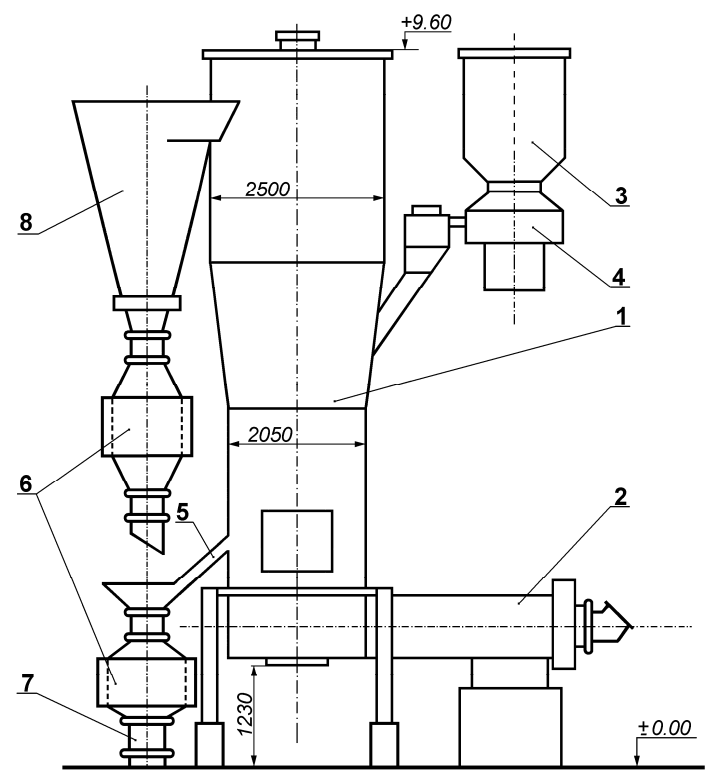

Fig. 1 - Plant for pyrrhotizing roasting

(1 - Fluidized bed furnace; 2 - fire-chamber; 3-bunker for concentrate; 4 - Feeder; 5 - unloading; 6 - accumulator-cooler; 7 - container; 8 cyclone)

\subsection{The second stage of roasting}

Fig. 2 shows the schematics for the two stage roasting operation. In the second stage, gasification of the remained sulphur takes place. It produces the $\mathrm{Fe}_{3} \mathrm{O}_{4}$ cinder, with the use of the cold air blowing on the layer at the temperature of $685-700^{\circ} \mathrm{C}$. The blowing air consumption is $900-1000 \mathrm{Nm}^{3} / \mathrm{m}^{2}$.hour. The oxygen consumption in the blowing was $0.14-0.175 \mathrm{Nm}^{3} / \mathrm{kg}$ of the concentrate.

At the second stage of roasting which is also carried out in furnaces of $\mathrm{KC}$ on the principle of the cold air blowing gases, waste gases are produced containing 8$10 \%$ of $\mathrm{SO}_{2}, 9-10 \%$ of $\mathrm{O}_{2}$ and nearly $0.5 \%$ of $\mathrm{SO}_{3}$. As a result of mixing of waste gases of two stages, gases are produced containing 16-17\% of $\mathrm{SO}_{2}, 0.1-0.5 \%$ of $\mathrm{O}_{2}$ and $0.1-0.15 \%$ of $\mathrm{SO}_{3}$. Processing of gases containing decreased quantity of $\mathrm{SO}_{3}$ let get less quantity of the washing acid, decrease corrosion influence on the dust trapping and gas piping systems, and increase the output of the finished product sulphuric acid. 


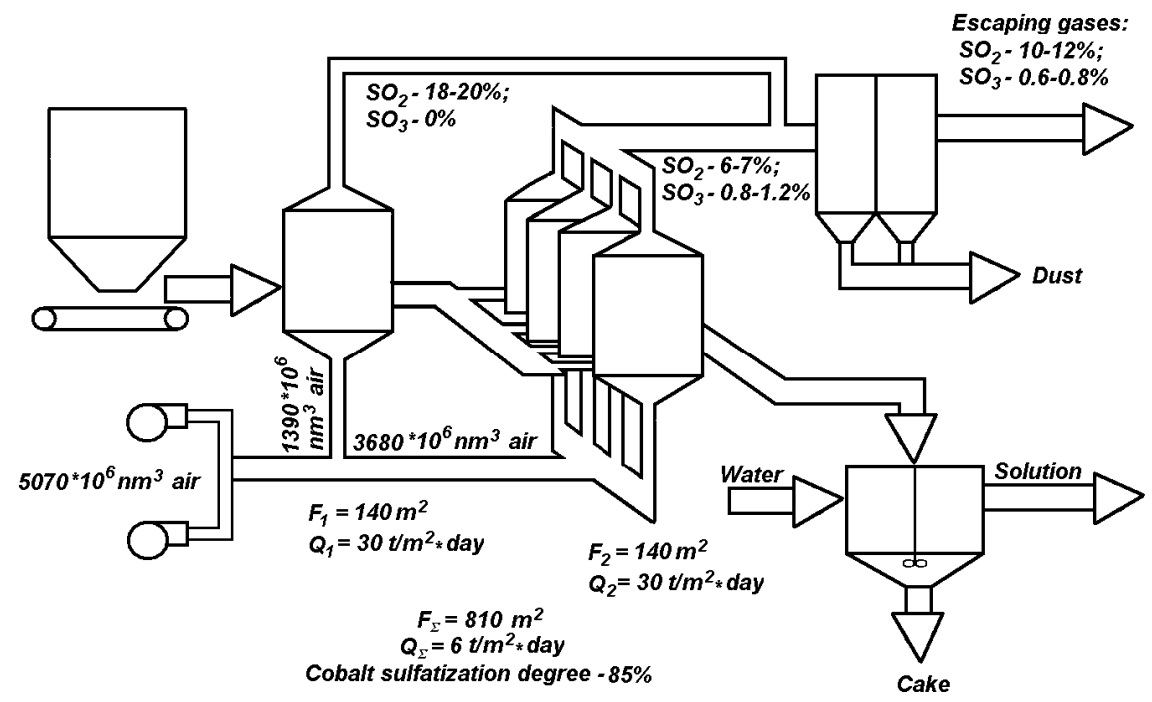

Fig. 2 - Principle scheme of two-stage roasting of pyrite concentrate

Decreased consumption of the blowing air in comparison with known technologies generate more concentrated gases and this is accompanied with less power consumption for lower blowing volume, less operational expenses for purification of produced gases, and the technology becomes more profitable.

\section{CONCLUSION}

We developed and checked in stages at an industrial-experimental scale for the technology of two-stage roasting of pyrite concentrates for producing rich sulphurous gas containing $0.1-0.15 \%$ of sulfur trioxide. The characteristics of the technology include:

- raise the temperature of roasting gases for $50-70^{\circ} \mathrm{C}$, which improves the corrosion resistance of the equipment and increases the productivity of roasting;

- lower the required roasting area of furnaces for $30-40 \%$;

- lower the blowing consumption by $30 \%$ at the expense of increasing the extent of the oxygen use and correspondingly raise the content of sulphur dioxide in roasting gases;

- simplify the system of dust-gas purification at the expense of decreasing the volume of roasting gases; lower the content of sulphur trioxide in roasting gases;

- make the technology more universal, suitable for processing raw materials containing different non-ferrous metals;

- lower the capital and operational expenses for roasting remake.

Thus, the use of the offered technology enables the production of sulfuric acid more economically by decreasing the concentration of sulfur trioxide from 0.5 to $0.1-$ 
$0.15 \%$, which improves the work of apparatuses of cooling and purification of roasting gases and increasing the sulfur dioxide concentration from $15 \%$ to $17 \%$.

\section{REFERENCES}

1. Luganov, V.A., Shabalin, V.I., Vasilevskiyi, O.V., 1982, “Autogenous pyrrhotizing roasting of pyrite concentrate". J. Chemistry and technology of chalcogenes and chalcogenides. № pp. $249-251$.

2. Vanyukov, A.V., Zaitsev, V.Ya., 1993, Theory of pyrometallurgical processes: Metallurgy, pp. 320, Moscow.

3. Tarasov, A.V., 2001, Production of non-ferrous metals and alloys: Metallurgy, v.1., pp. 410, Moscow.

4. Method of processing of cobalt containing pyrite concentrates: Patent № 1591497, M.: 1990.

5. Method of processing of sulfide raw materials. Preliminary patent. № (19) KZ (13) A(11) 16457 (51) C22B 1/02. Almaty: 2005.

6. Habashi, F. "Clean Technology in the Metallurgical Industry". International conference: Metallurgical high technology and new materials of heavy nonferrous metals. April 3-5, 2002, Kunming, China, pp. 521-531. 